\title{
Instrument for benzene and toluene emission measurements of glycol regenerators
}

\author{
Veronika Hanyecz ${ }^{1}$, Árpád Mohácsi ${ }^{2}$, Sándor Puskás $^{3}$, Árpád Vágó $^{3}$, Gábor Szabó ${ }^{1,2}$ \\ ${ }^{1}$ Department of Optics and Quantum Electronics, University of Szeged, Dóm tér 9, H-6720 \\ Szeged, Hungary \\ ${ }^{2}$ MTA-SZTE Research Group on Photoacoustic Spectroscopy, Dugonics tér 13, H-6720 \\ Szeged, Hungary \\ ${ }^{3}$ MOL Plc. Exploration \& Production Division, IFA New Technologies and R\&D, Pf. 37, H- \\ 6701 Szeged, Hungary
}

\begin{abstract}
We introduce an in-field and in-explosive atmosphere useable instrument, which can measure the benzene and toluene concentration in two gas and two glycol samples produced by natural gas dehydration units. It is a two-phase, on-line gas chromatograph with a photoacoustic spectroscopy based detector. The time resolution is $10 \mathrm{~min}$ per cycle and the minimum detectable concentrations are $2 \mathrm{mg} \mathrm{m}^{-3}$ for benzene, $3 \mathrm{mg} \mathrm{m}^{-3}$ for toluene in natural gas, and $5 \mathrm{~g} \mathrm{~m}^{-3}$ for benzene and $6 \mathrm{~g} \mathrm{~m}^{-3}$ for toluene in glycol. Test measurements were carried out at a dehydration plant belonging to MOL Hungarian Oil and Gas Company. Benzene and toluene emissions of gas dehydration unit are calculated from measured values based on mass balance of glycol regenerator. Relationship between the outdoor temperature and measured concentration was observed that is caused by temperature dependent operation of the whole dehydration unit. Emission decreases with increase of outdoor temperature.
\end{abstract}

Keywords: benzene, toluene, emission, glycol regeneration, gas dehydration, chromatography

\section{Introduction}

Natural gas dehydration plants are potential BTEX (benzene, toluene, ethyl-benzene and xylenes) emission sources. The most widely used dehydration method is absorption by mono-, di-, or triethylene glycols (EG, DEG and TEG) [1,2]. DEG and TEG units contain a contactor where glycol absorbs water from wet gas (originating from natural gas during pre-separation), 
while EG is sprinkled to wet gas stream and functions as a hydrate inhibitor. After separating the liquid phase from dry gas, rich (watered) glycol is regenerated by heating (arising glycol called lean glycol). Natural gas contains BTEXs, and because they are very soluble in glycol they tend to accumulate in it. Since aromatic compounds are very volatile, the majority of them leave the regenerator along with boiled water. Quantification their emission is very important for environmental protection [3, 4].

Concentrations of ethyl-benzene and xylenes in natural gas are two orders of magnitude lower than that of benzene and toluene [5], moreover, benzene is carcinogenic [6], thus development focuses on benzene and toluene. Previously an instrument with a photoacoustic detector was developed to determine benzene and toluene concentrations in natural gas and in glycol samples produced in a natural gas dehydration unit. The detection is based on a phenomenon whereby a sound wave is formed if material is illuminated by a modulated light beam with characteristic wavelength. The molecules absorb the light, come to an excited state and they relax in non-radiative way. It causes periodic temperature variation and thereby periodic pressure variation (i.e. sound) that is detected by a microphone [7]. The prototype was capable of selectively measuring benzene and toluene in one gas and two liquid samples within appropriate detection limits; it had compact design and was operated automatically [5]. However, it could be used solely under laboratory conditions and according to the European Standard on equipment for explosive atmospheres (ATEX) the instrument is qualified as an electrical equipment containing spark sources and dehydration plants are mentioned as potentially explosive areas [8]. Moreover, gas sampling required modification due to continuously changing gas composition. Sampling was made by a mass flow controller (MFC), which operates on the basis of thermal conductibility depending on gas composition.

The present paper introduces the final, explosion-proof (EX) version of the instrument with field measurements conducted in parallel with a gas-chromatograph are shown. Emission values were calculated from concentration values.

\section{Experimental}

\subsection{Instrument set-up}

A schematic diagram of the gas and liquid handling part of the instrument can be seen in Fig.1. The whole system is built into an 800x650x1800 mm standard outdoor cabinet with IP55 protection (Rittal Ltd.). Inside it is a stainless steel instrument box $(600 \times 300 \times 800 \mathrm{~mm})$ 
with overpressure venting protection which contains all non-EX electrical devices (including MFC, solenoid valves (SV), electronic unit, etc.).

Figure 1

Dry and wet gases at a pressure of 0.5 bar are connected to the gas inlet ports. In both lines there are pneumatic valves (PN1 and PN2) which are open if all explosion protection conditions are complied. In both gas lines there are accelerating lines, their flow rates are set to $31 \mathrm{~min}^{-1}$ by needle valves. There is a T-junction in the dry gas line, after the needle valve. One line connects to the SV1 valve, the other line connects to the gas outlet port through a rotameter (R2). This second port functions as an accelerating line refreshing dry gas. In the wet gas line, after the needle valve there is a liquid trap with a drop-catcher because wet gas could contain liquid hydrocarbons. The upper outlet of the trap connects to SV1, while the lower outlet functions as an accelerating line and goes to gas outlet port through R3. One can choose between dry and wet gas by SV1. The SV2 valve is open only during gas sampling. Then the pump draws gas through the adsorbent. The gas outlet port is equipped with a ball check valve to prevent the reflux of gas and an insect trap. This outlet port collects not just accelerating but other gas lines including the gas outlet of the piston pump.

Both lean and rich glycol lines are equipped with $100 \mu \mathrm{m}$ pore size stainless steel filters to protect the instrument from solid contaminants. One can choose between glycols with SV11. The refreshing of the glycol sample is provided by pumping through SV11, SV9 and SV8. The liquid outlet port is connected to the dehydration unit and transports glycols back to the rich glycol line. Liquid is trapped in tubes between SV8 and SV9. It ensures that the volume of sampled glycol is always the same. Benzene and toluene from trapped glycol get to the adsorbent due to bubbling extraction which is carried out by nitrogen and takes place in a glycol-gas contactor. It is made of copper and temperature stabilized at $40^{\circ} \mathrm{C}$.

For both gas and liquid the purpose of sample preparation is getting measured components to the adsorbent. Then the adsorbent is heated until thermodesorption occurs and adsorbed molecules are carried by nitrogen flow controlled by an MFC to the column and detected by a photoacoustic detector (PAD). The adsorbent is a glass tube with a $4 \mathrm{~mm}$ inner diameter, filled in $8 \mathrm{~cm}$ length with graphitized carbon black (Carbotrap X, 20/40 mesh, adsorbed analytes: BTEX, $\mathrm{C}_{5-8}$ hydrocarbons). The column is a $60 \mathrm{~cm}$ long stainless steel tube with $4 \mathrm{~mm}$ inner diameter, filled with bis-methoxy-ethyl-adipate/Chromosorb PAW (80/100 mesh). It is temperature stabilized at $60^{\circ} \mathrm{C}$. The PAD consists of the following parts: a diode 
laser (NLK1U5E1AA, NEL Inc., radiating around $1669 \mathrm{~nm}$ ) as light source, an electret microphone (Knowles EK 3029, Knowles Inc.) as sound detector and a photoacoustic cell made from stainless steel, being temperature stabilized at $50^{\circ} \mathrm{C}$. Geometry of the cell is identical to thus used in our previous works [5, 7]. Selectivity for BTEX is ensured by adsorbent, column and detection together, because numerous analytes that could influence the detection (including methane) do not adsorb on Carbotrap X. In addition, the adsorbed ones have a several orders of magnitude lower adsorption coefficient at the tuning range of the diode laser $(1669 \pm 1 \mathrm{~nm})$ than benzene and toluene. The separation of aromatic compounds is carried out on a column, because they are indistinguishable with a spectroscopic technique at this wavelength range [9].

Instrument air (at this gas plant: 6 bar pressure, dew point temperature below $-20^{\circ} \mathrm{C}$, oily) is essential for the operation of this system. It performs several functions: first, it provides overpressure protection; second, it carries out control and operation of pneumatic pump; and finally it controls pneumatic valves (PN1 and PN2). Instrument air lines are not shown in Fig.1.

The pneumatic pump has two sampling pistons, one for gas and one for liquid, which both circulate together. The gas and liquid sampler cylinders are $350 \mathrm{ml}$ and $75 \mathrm{ml}$, respectively, so the volumes of samples are $700 \mathrm{ml}$ and $150 \mathrm{ml}$ during one cycle. The gas and liquid are circulated by slave cylinders which are operated by instrument air. One cycle, meaning one back and forth movement of pistons is started by a pressure impulse, turned and stopped by end switches. The pistons can move at two speed rates, a fast one (10 cycles per minute) and a slow one (1 cycle per minute). Changing between speed rates can be carried out by a pneumatic valve. After one cycle the piston movement is stopped until it gets another starting impulse.

Tubing is made of stainless steel or polyethylene. The latter is used only for gas or glycol outlet and instrument air.

Numerous explosion protection conditions must be complied with. Some of them are detailed in the following sections. First, there are two gas detectors (EXTOX-UNI K2, not shown in Fig.1.) inside the box which switch off the instrument if the methane concentration reaches $20 \%$ of the explosive limit. Second, inside the overpressure protection box definite pressure must prevail which is 5 mbar higher than atmospheric pressure (pressure regulator: BARTEC APEX 2013). This overpressure is obtained by instrument air. After switch-on, before the instrument starts operating, the whole air space of the overpressure protection box 
is rinsed through by instrument air. The volume of the rinsing air must be at least three times greater than the volume of the overpressure box.

There are Pt100 temperature sensors inside the overpressure box and the outdoor cabinet. Both of them have a control function. The temperature inside the overpressure protection box can be high (more than $40^{\circ} \mathrm{C}$ ), because electrical devices generating heat and sunlight can warm the whole instrument. If a sensor perceives that the temperature reaches $40^{\circ} \mathrm{C}$, a Peltier cooler is switched on, which has a heat sink outside the overpressure box. It is cooled by instrument air flow. In the outdoor cabinet there is an electrical, EX heater as freeze protection, which is switched on below $10^{\circ} \mathrm{C}$.

\subsection{Measurement cycle}

The measurement cycle can be followed in Fig. 1. The 3/2 solenoid valves have three ports, one is the common (C in Fig.1.), the others are normally open (1) and normally closed (2). Two positions are allowable: the connection of normally open with common and normally closed with common ports. Gas and/or liquid can flow in both directions (from normally open/closed to common or from common to normally open/closed ports). Normally open and normally closed ports can not be connected. The $2 / 2$ solenoid valves are either closed or open. Valves can be controlled by electricity.

The parts of the gas measurement process are the following: sampling of gas and recording the chromatogram. First the measured gas is chosen by SV1. SV2 is opened, SV5 is set to position 2, and the pump draws gas through the adsorbent. MFC and SV7 are closed; SV4 is set to position 1. The speed rate of the piston movement is slow to support the adsorption process. The sampling volume is $700 \mathrm{ml}$ (one cycle of movement). Thereafter the chromatogram is recorded. Nitrogen flow is adjusted to $10 \mathrm{~cm}^{3} \mathrm{~min}^{-1}$ by MFC, SV2 is closed, SV5 is set to position 1 and SV7 is opened. The heating of the adsorbent is started and desorbed molecules are carried to the column to be separated in time. In the PAD the detection occurs.

The parts of liquid measurement are the following: flowing of glycol, bubbling extraction and recording the chromatogram. First the measured glycol is chosen by SV11. SV8 and SV9 are set to position 1 and the pump draws glycol through these valves. The output port of the pump is connected to the rich glycol line of the regenerator. The speed rate of piston movement is fast. Approximately $500-600 \mathrm{ml}$ glycol is passed, so there are 3-4 cycles of piston movement. The purpose of this step is to refresh the glycol sample trapped in the tube 
between SV8 and SV9 (glycol trap in Fig.1.). Then bubbling extraction is carried out by opening SV3, and setting SV10, SV9, SV8, SV4 and SV5 to position 2, while nitrogen controlled by R1 is bubbled through trapped glycol in the glycol-gas contactor to carry components to the adsorbent. The nitrogen flow rate is $\sim 1.11 \mathrm{~min}^{-1}$. The next step is recording the chromatogram. It is similar to the case of gas except that the glycol sample is removed from the contactor during the measurement. SV4 and SV10 are set to position 1, so the flow direction of nitrogen in glycol-gas contactor changes and it carries glycol sample to collector tank.

The whole system operates automatically controlled by an integrated electronic unit. It can simultaneously measure only one sample, which takes $\sim 10 \mathrm{~min}$. Every sample is measured three times sequentially and in one measurement cycle all four sample is analyzed. Therefore one cycle takes $\sim 2 \mathrm{~h}(3 \times 4 \times 10 \mathrm{~min})$.

\subsection{Data evaluation}

According to our experience, former sample affects the first chromatogram therefore the other two chromatograms were used for all samples. The multiple segment trapezoidal rule was used to calculate the area under peak (called instrument response). The two areas were averaged and it is directly proportional to the concentration [5].

Emission was calculated from the mass balance of glycol regenerator in the following way:

$$
e_{\mathrm{x}}\left(\frac{\mathrm{g}}{\mathrm{h}}\right)=Q_{\mathrm{r}}\left(\frac{\mathrm{m}^{3}}{\mathrm{~h}}\right) \cdot c_{\mathrm{r}, \mathrm{x}}\left(\frac{\mathrm{g}}{\mathrm{m}^{3}}\right)-Q_{1}\left(\frac{\mathrm{m}^{3}}{\mathrm{~h}}\right) \cdot c_{\mathrm{l}, \mathrm{x}}\left(\frac{\mathrm{g}}{\mathrm{m}^{3}}\right)-Q_{\mathrm{w}}\left(\frac{\mathrm{m}^{3}}{\mathrm{~h}}\right) \cdot c_{\mathrm{w}, \mathrm{x}}\left(\frac{\mathrm{g}}{\mathrm{m}^{3}}\right)
$$

where $\quad Q: \quad$ hourly amount of glycol

$c: \quad$ concentration of benzene/toluene

r/l in index: rich/lean glycol

w in index: condensate from vapor (water)

$\mathrm{x}$ in index: benzene or toluene.

Glycol regenerator is introduced as part of glycol dehydration unit in Test measurement section.

\subsection{Test measurement}

The instrument was calibrated with samples containing known amount of components [5]. 
Test measurements were carried out at a gas plant of MOL, whose schematic diagram can be seen in Fig.2. The purpose of drying is to transmute natural gas into pipe-transportable form. The first step is to separate free water and liquid hydrocarbons (condensate) from gas in a pre-separator. Then lean EG is added to wet gas. In the ammonia cooling unit the gas-glycol mixture is cooled to $-5^{\circ} \mathrm{C}$. Thereafter the mixture goes to the cold separator $\left(20 \mathrm{bar},-5^{\circ} \mathrm{C}\right)$. The separated phases are dry gas and liquid containing rich glycol and liquid hydrocarbons. Dry gas is transported to another gas plant. The liquid phase is directed to the three-phase separator $\left(4 \mathrm{bar}, 30^{\circ} \mathrm{C}\right)$, where rich glycol and liquid hydrocarbons (with gases) are separated. The liquid phase is warmed up by a heat exchanger (not shown in Fig.2.). Rich glycol is transported to the regenerator, where it is heated to $110^{\circ} \mathrm{C}$, which is higher than the boiling point of water but lower than that of glycol, so water is boiled off. The arising lean glycol is recycled in the process. The vapor is cooled to outdoor temperature and the majority of that (mainly water) condensates. However, the majority of aromatic compounds leave the regenerator as vapor, because they are very volatile and soluble in water bad.

Fig. 2. show places of sampling for measurements; 1-wet gas, 2-dry gas, 3-rich glycol, 4lean glycol. There was a parallel measurement with a gas-chromatograph (Agilent 7890; FID and TCD detector; with three columns: Porapak R, HP-1, Molsieve 13X; suitably of ISO 6974 and ISO 6975); its sampling points were the same.

Figure 2

\section{Results and discussion}

The minimum detectable concentrations (MDCs) were determined as three times the standard deviation of instrument response measured at zero concentration divided by the slope of the calibration curve. The curves are very similar to those presented in our previous work [5], consequently only MDCs are reported. They were found to be $2 \mathrm{mg} \mathrm{m}^{-3}$ for benzene, $3 \mathrm{mg} \mathrm{m}^{-3}$ for toluene in gas, and $5 \mathrm{~g} \mathrm{~m}^{-3}$ for benzene and $6 \mathrm{~g} \mathrm{~m}^{-3}$ for toluene in glycol.

A two week period of measured concentration data, temperature of outdoor cabinet and calculated and normalized emission is shown in Fig. 3. Emission values were calculated with (1). $Q_{1}$ was given from pump characteristic. The concentration of lean glycol is $\sim 80 \%$, (the remaining $20 \%$ is water) while that of rich glycol is $\sim 70 \%$, thus $Q_{\mathrm{r}}$ was known. It was established that the third part of the equation is negligible, because daily amount and concentrations for condensate are much less than for that of glycols. This condensate consists 
of mainly water and aromatics poorly soluble in water. $c_{\mathrm{r}}$ and $c_{1}$ were the measured data. The calculated emissions were normalized to the average value.

Continuous measurement was performed for two weeks. Concentration values are incomplete only for rich glycol, because it could contain liquid hydrocarbons, which causes uninterpretable chromatograms. As it was expected, the concentrations in wet gas and rich glycol are higher than in dry gas and lean glycol, respectively. Concentrations are relatively constant. The pressure of pre-separator was 20 bar, but between noon on the $3^{\text {rd }}$ of June and noon on the $5^{\text {th }}$ of June it was 60 bar. This caused concentration decrease in gases, because more aromatics get to liquid phase on higher pressure at same temperature.

GC measurements were performed on the $5^{\text {th }}$ of June for gas and on the $29^{\text {th }}$ and $30^{\text {th }}$ of May for glycol. The gas data measured by the two methods were found to agree remarkably well especially for toluene. In glycol, the concentrations for benzene are similar, but for toluene GC measured three times lower value. GC is an off-line method in this case, its sampling was made on the above listed days, but analysis was performed days or weeks later. Moreover, there is no limit value for aromatic compounds in natural gas, therefore the determination of BTEX in natural gas is not a routine task. In addition, analysis of glycol is not a prescription at all.

The temperature of outdoor cabinet represents best (from among the measured temperatures) the outdoor temperature. If the concentrations and emissions are studied parallel with temperature, a relationship can be observed. It is very characteristic after the $6^{\text {th }}$ of June, when the weather was warmer and it is most obvious for toluene in dry gas. In rich glycol and in emission (both mainly for benzene) inverse proportion can be noticed.

It is caused probably by the temperature-dependence of the whole dehydration system. The detection is not temperature-dependent, because all main parts of the instrument (glycolgas contactor, column, PAC) are temperature-stabilized and adsorption on Carbotrap $\mathrm{X}$ is temperature-independent in this range (approximately $20-50^{\circ} \mathrm{C}$ ). But it is well known that the vapor-liquid-liquid equilibrium greatly depends on temperature (and pressure). The examined unit contains two separators where this equilibrium is very important. If the temperature of the cold separator increases, the benzene and toluene concentration in dry gas will increase and therefore the concentrations in oil-rich glycol mixture will decrease. Provided that the temperature of the three-phase separator is constant, it is verifiable that concentration in rich glycol will decrease. The concentrations in lean glycol are less temperature-dependent, because regenerating of glycol is a priori a hot process. Finally, emission is inversely 
proportionate to temperature. It corresponds very well for benzene, but also could be observed for toluene.

Figure 3

\section{Conclusion and outlook}

A field-usable, two-phase, EX, process chromatograph with photoacoustic detector was introduced which is capable of measuring benzene and toluene concentrations in gas and glycol samples produced in natural gas dehydration units. Selectivity to benzene and toluene is provided by adsorbent, column and detector together. MDCs were found to be $2 \mathrm{mg} \mathrm{m}^{-3}$ for benzene, $3 \mathrm{mg} \mathrm{m}^{-3}$ for toluene in gas, and $5 \mathrm{~g} \mathrm{~m}^{-3}$ for benzene and $6 \mathrm{~g} \mathrm{~m}^{-3}$ for toluene in glycol, which are adequate to meet the requirements of the present application.

The instrument has a response time of 2 hours, which is appropriate to follow concentration changes in wet and dry gas as well as in rich and lean glycol. Emission was calculated from mass balance of glycol regenerator. Outdoor temperature dependence was found for concentrations and also emission.

The simulation of emission of gas dehydration plants is widespread. TEG units are relatively well known [10,11], but EG units are rarely studied [12]. The next aim is to model the studied EG unit by HYSYS simulation software (Aspen Technology Inc.) and compare the measured and simulated data. A promising direction can be the parallel examination of the emission when changing the temperature of cold separator to confirm our results.

\section{Acknowledgements}

The research of Veronika Hanyecz was supported by the European Union and the State of Hungary, co-financed by the European Social Fund in the framework of TÁMOP 4.2.4.A/211-1-2012-0001 'National Excellence Program'. The other members of the research team and the equipment purchase were supported by TÁMOP-4.2.2A-11/1/KONV-2012-0060 and MOL Ltd (UX 8307.11.53/95). 


\section{References}

1. Hidnay A J, Parrish W R 2006 Fundamentals of Natural Gas Processing Taylor and Francis Group ISBN-10: 0-8493-3406-3

2. Netusil M, Ditl P 2011 Comparison of three methods for natural gas dehydration $J$. Nat. Gas Chem. 20 471-6

3. Directive 2000/69/EC of the European Parlaiment and of the Council of 16 November 2000 relating to limit values for benzene and carbon monoxide in ambient air, http://eur-

lex.europa.eu/LexUriServ/LexUriServ.do?uri=OJ:L:2000:313:0012:0021:EN:PDF

4. Air Quality Guidelines for Europe 2000 WHO Regional Publications

5. Hanyecz V, Mohácsi Á, Puskás S, Vágó Á, Szabó G 2011 Photoacoustic spectroscopybased detector for measuring benzene and toluene concentration in gas and liquid samples Meas. Sci. Technol. 22125602 (7pp)

6. Smith M T 2010 Advances in Understanding Benzene Health Effects and Susceptibility Annu. Rev. Publ. Health 31 133-48

7. Bozóki Z, Pogány A, Szabó G 2011 Photoacoustic Instruments for Practical Applications: Present, Potentials and Future Challenges Appl. Spectrosc. Rev. 46 137.

8. Guidelines of Directive 94/9/EC of the European Parliament and the Council of 23 March 1994 on the approximation of the laws of the member states concerning equipment and protective systems intended for use in potentially explosive atmospheres,

http://ec.europa.eu/enterprise/sectors/mechanical/files/atex/guide/atexguidelinesmay2011_en.pdf

9. Mohácsi Á, Bozóki Z, Niessner R 2001 Direct diffusion sampling-based photoacoustic cell for in situ and on-line monitoring of benzene and toluene concentration in water; Sensor. Actuat. B 79 127-31

10. Darwish N A, Hilal N 2007 Sensitivity analysis and faults diagnosis using artificial neural networks in natural gas TEG-dehydration plants Chem. Eng. J. 137 189-97

11. Break A M, Almehaideb R A, Darwish N, Hughes R 2001 Optimization of process parameters for glycol unit to mitigate the emission of BTEX/VOCs Process Saf. Environ. 79 218-32 
12. Alva-Argaez A, Holoboff J L, Khoshbarchi M 2012 BTEX emissions from ethylene glycol circulation in natural gas refrigeration plants: a process simulation study GPA 91st Annual Convention Proceedings P2012.09 


\section{Caption of figures}

Figure 1: Schematic diagram of the instrument showing gas and liquid circulation.

Figure 2: Schematic diagram of the gas plant.

Figure 3: Field measurement results. $a, b$ and $c$ : concentration in gas, in glycol and emission for benzene; $e, f$ and $g$ : concentration in gas, in glycol and emission for toluene; $d$ and $h$ : temperature of outdoor cabinet. Concentration in gas: solid line - wet gas, dashed line - dry gas; square symbol - wet gas with GC, triangle symbol - dry gas with GC. Concentrations in glycol: solid line - rich glycol, dashed line - lean glycol; square symbol - rich glycol with GC, triangle symbol - lean glycol with GC. Calculated benzene and toluene emissions are normalized to average emission value; points: normalized emission values, lines: five-point moving average trend lines.

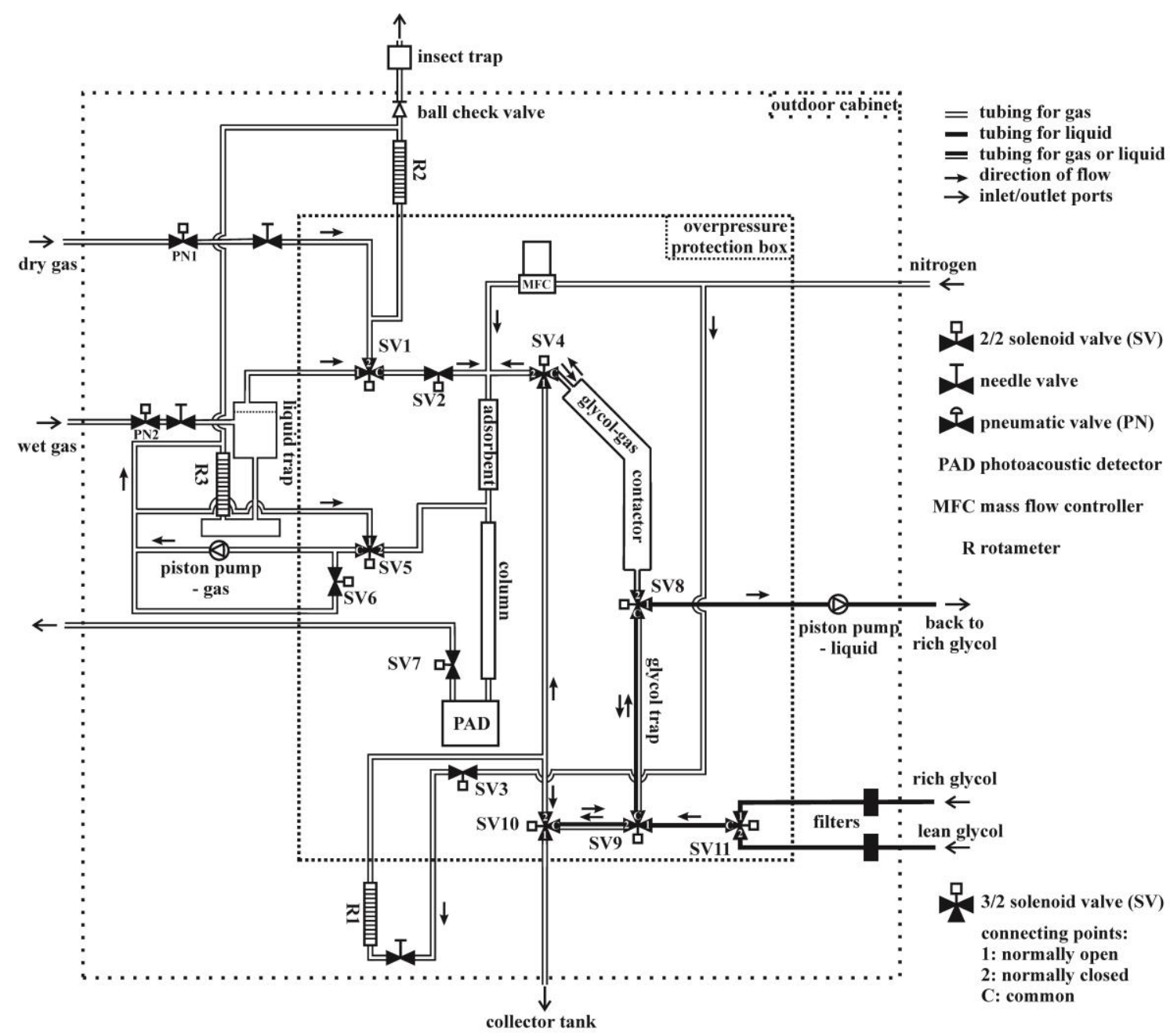



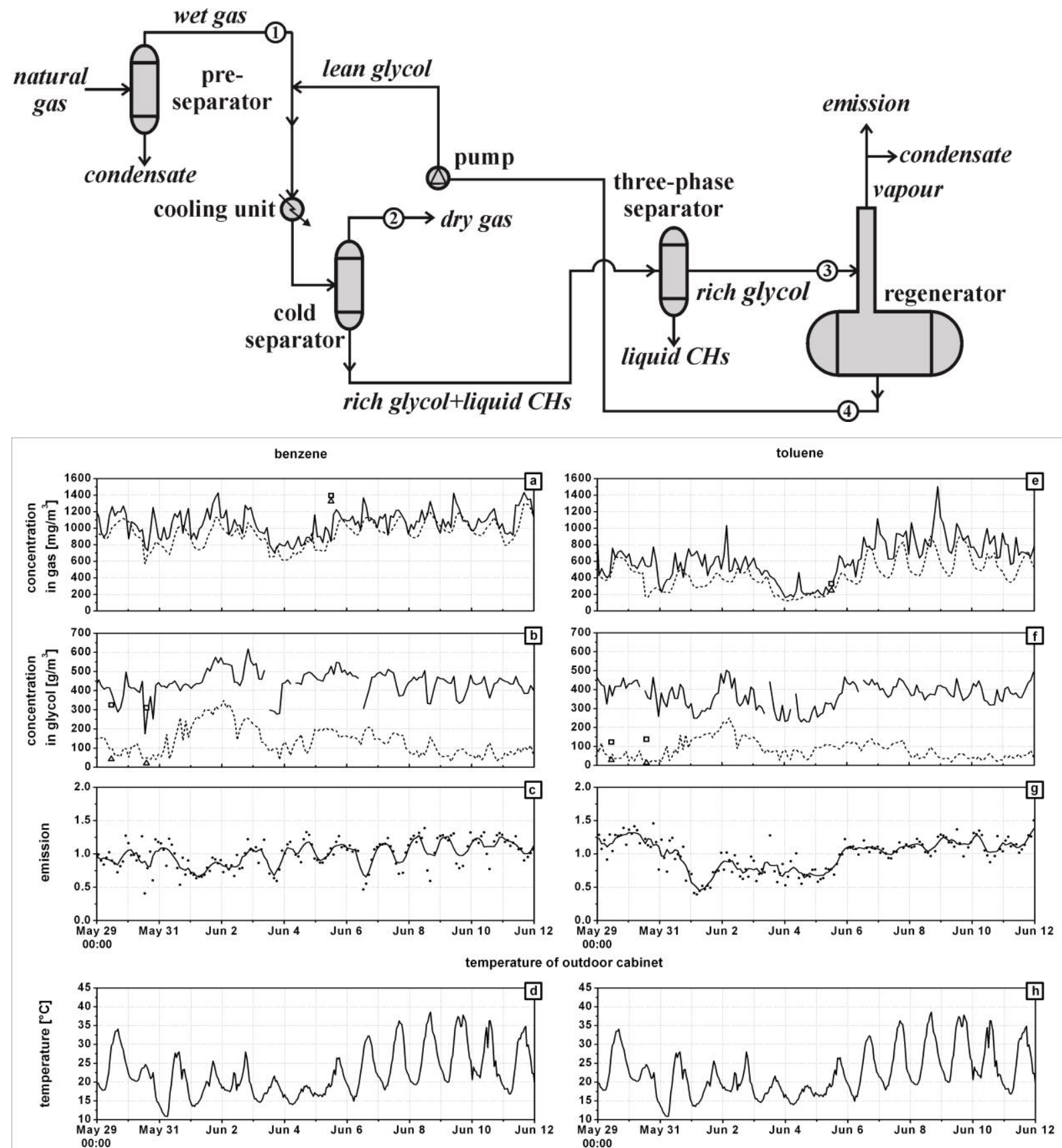